Research Paper

\title{
Lyophilized Powder of Catalpol and Puerarin Protects Neurovascular Unit from Stroke
}

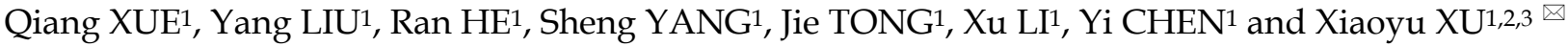 \\ 1. College of Pharmaceutical Sciences \& College of Chinese Medicine, Southwest University, Chongqing 400715, China; \\ 2. Chongqing Engineering Research Center for Pharmacological Evaluation, Chongqing 400715, China; \\ 3. Institute of Chinese Medicine, Southwest University, Chongqing 400715, China.
}

$\square$ Corresponding author: Professor Xiaoyu XU, Laboratory of Molecular Pharmacology, College of Pharmaceutical Sciences \& College of Chinese Medicine, Southwest University, Chongqing 400715, China. Tel.: +86-23-6825-0761; Fax: +86-23-6825-1225; E-mail: xuxiaoyu@swu.edu.cn.

(1) Ivyspring International Publisher. Reproduction is permitted for personal, noncommercial use, provided that the article is in whole, unmodified, and properly cited. See http://ivyspring.com/terms for terms and conditions.

Received: 2015.10.06; Accepted: 2015.12.08; Published: 2016.01.28

\begin{abstract}
Hunting for an effective medicine for brain stroke has been a medical task in neuroscience for decades. The present research showed that the lyophilized Powder of Catalpol and Puerarin (C-P) in all the tested doses $(65.4 \mathrm{mg} / \mathrm{kg}, 32.7 \mathrm{mg} / \mathrm{kg}, 16.4 \mathrm{mg} / \mathrm{kg})$ significantly reduced the neurological deficiency, infarct volume and apoptotic cells in ischemic/reperfusion (I/R) rats. It also promoted astrocyte processes and prolonged neuron axons in infarct area. Further, it decreased MDA, NO, NF-KB/p65, TNF- $\alpha$, IL- $1 \beta$ and IL-6 and enhanced the EPOR and GAF-43. $65.4 \mathrm{mg} / \mathrm{kg}$ and 32.7 $\mathrm{mg} / \mathrm{kg}$ C-P could up-regulated EPO and VEGF significantly. In vitro, $49 \mu \mathrm{g} / \mathrm{mL}$ and $24.5 \mu \mathrm{g} / \mathrm{mL}$ C-P decreased the leakage of sodium fluorescein and increased the activity of $Y$-GTP. Additionally, it increased SOD and decreased MDA, NO, and LDH and decreased NF-KB/P65, TNF- $\alpha$, IL-1 $\beta$ and IL-6 and unregulated EPO, EPOR, VEGF, and GAP-43. Only the dose of $49 \mu \mathrm{g} / \mathrm{mL}$ increased TEER and Claudin-5 and turned the typically damaged morphologies of neurons, astrocytes and endothelium into a favorable trend. These data imply that C-P improved the recovery of neurological deficiency in motor, sense, balance and reflex, and protected the whole NVU by anti-oxidative stress, anti-inflammation and up-regulating some protective factors. This research provides a candidate medicine for brain stroke and, at the same time, a pattern for drug study targeting NVU in vitro.
\end{abstract}

Key words: Neurovascular Unit; Lyophilized Powder of Catalpol and Puerarin; Brain stroke; Oxygen and glucose deprivation; Neuroprotection.

\section{Introduction}

Although Recombinant Tissue Plasminogen Activator performs excellently on stroke, very few (about $5 \%$ ) stroked patients in acute period were benefit from the drug $[1,2]$ because of the short time-window of treatment and high risk of hemorrhage [3, 4]. Researchers have been developing an alternative one for the disease for more than 50-year, however, as American Stroke Association highlighted in 2013, there is no one drug available for stroke as a neuroprotective agent [5]. So, what is responsible for those failures? Increasing researchers point out the main cause of the failures is that the treatment only targets one type of cerebral cells rather than a func- tional unit. Based on this, a new idea came out that the treatment of brain stroke should target the whole functional unit, the Neurovascular Unit (NVU).

NVU, mainly consisting of microvessels, astrocytes, neurons, extracellular matrix and other types of gliocytes is defined as a whole functional and structural unit of brain [6]. It is regarded that not only neurons suffer from stroke, but also the microvasculature and gliocytes are involved [7]. And the interactions among these types of cells are crucial for treating the disease [7]. Hence, the protection on Neurovascular Unit becomes the most potential strategy to conquer brain stroke $[8,9]$. 
Based on this strategy, we have established a NVU model for in vitro study. It is a triple-cell co-culture system which consists of three kinds of primary cells including neurons, astrocytes and microvascular endothelial cells. We further observed several crucial pathologies of brain stroke on this model via OGD/R, which suggests the applicability of the model in brain research and screening for related candidates [10].

Lyophilized Powder of Catalpol and Puerarin is a preclinical candidate consisting of Catalpol and Puerarin which are two pharmacologically effective ingredients isolated from Rehmannia glutinosa Libosch and Radix Puerariae, respectively. Previous studies have convinced the safety of the medicine and the ability of crossing BBB [11, 12]. It also performed an excellent anti-stroke on permanent middle cerebral artery occlusion mouse with prominent anti-oxidative stress injury, anti-apoptosis, and promoting angiogenesis and neurogenesis [13]. Additionally, C-P protected human umbilical vein endothelial cells from inflammation, oxidative stress injury and apoptosis [14].

This research will evaluate the protection of C-P on NVU on I/R rats and OGD/R-damaged NVU models in vitro. It will cover pathologically and protectively crucial sides including the permeability of BBB, oxidative stress injury, inflammation and some protective factors.

\section{Materials and methods}

\section{Animals}

All experiments follow an institutionally approved protocol in accordance with the China's Guidelines for Care and Use of Laboratory Animals. Sprague-Dawley rats were purchased from the Experimental Animal Center, Chongqing Research Institute of Chinese Medicine (Chongqing, China) and housed under controlled environment $\left(22 \pm 2^{\circ} \mathrm{C}, 12 \mathrm{~h}\right.$ light/dark cycle, free access to food and water) in the Experimental Animal Center, College of Pharmaceutical Sciences, Southwest University (Chongqing, China). 0-10 day rats were sacrificed for isolating the three types of the primary cells, and 260-300 g male rats were performed the I/R model.

\section{Reagents}

The Catalpol and Puerarin (purity $>98 \%$ ) were purchased from Liu bo bai niao Biological Technology Co., Ltd (Hebei, China). The lyophilized Powder of Catalpol and Puerarin was prepared in our Lab. Fetal Bovine Serum (FBS), DMEM/F12, and B27 were purchased from GIBCO (Gaithersburg, MD, USA). MTT, trypsin, L-glutamine, EDTA, gelatin, sodium fluorescein (SF), Collagenase type II B Bull Serum Albumin (BSA) and L-polylysine were purchased from Sigma-Aldrich (St Louis, MO, USA). Except that the anti-TNF-a antibody was from Cell Signaling Technology, all the antibodies used in this research were purchased from Proteintech Group, Inc. (Chicago, IL, USA) and kits from YUANYE-BIO (Shanghai, China)

\section{Quality control of C-P by HPLC [15]}

The qualitative control of C-P was performed on HPLC (Agilent 1200, USA). Chromatographic conditions: column Agilent Zorbax SB-C18 $(4.6 \mathrm{~mm} \times 250$ $\mathrm{mm}, 5 \mu \mathrm{m}$ ); eluent: water and acetonitrile (Adamas-beta Co., Ltd, Shanghai, China) for gradient elution; the monitoring wavelength was set at $210 \mathrm{~nm}$ for catalpol and puerarin; flow rate was $1.0 \mathrm{ml} / \mathrm{min}$ and the column temperature was $30^{\circ} \mathrm{C}$; the sample size was $10 \mu 1$. The HPLC analysis was validated and met the methodological requirements.

\section{Establishment of $I / R$ rats}

The establishment of $\mathrm{I} / \mathrm{R}$ rats was performed as previous report [16]. Basically, SD rats were anesthetized with $4 \%$ chloral hydrate for surgery after 3-daypre-training of balance beam. After midline skin incision, a length of 4-0 monofilament nylon suture was put into the left external carotid artery to occlude the Middle Cerebral Artery. 2 hours later, the line was removed away for reperfusion. During the whole surgery, rats were kept in temperature of $37^{\circ} \mathrm{C}$. The rats for sham operation suffered the same with $I / R$ rats but without putting the line into artery.

\section{Screening the qualified I/R rats by behavioral test}

After scored by modified neurological severity scores (mNSS) which consists of motor, sensory, reflex, and balance tests [17], only I/R rats whose neuroscores (Figure 1) were not below 4 were regarded as qualified candidates for following tests.

\section{Animal groups and treatments}

72 qualified rats were numbered and then averagely divided into 4 groups of I/R and three gradient doses of C-P $(65.40 \mathrm{mg} / \mathrm{kg}, 32.7 \mathrm{mg} / \mathrm{kg}$, and $16.4 \mathrm{mg} / \mathrm{kg}$ ) by completely randomized digital table. The neuroscore of each group was evaluated by mNSS to confirm no significant differences between groups (Table 1). Another 18 rats were for sham. The first administration of C-P was performed by a tail intravenous injection after rats were grouped, and the last was 12 hours later. The duration of the treatment with C-P was 24 hours. The sham group and I/R group were given the normal saline with the same volume of C-P groups. 


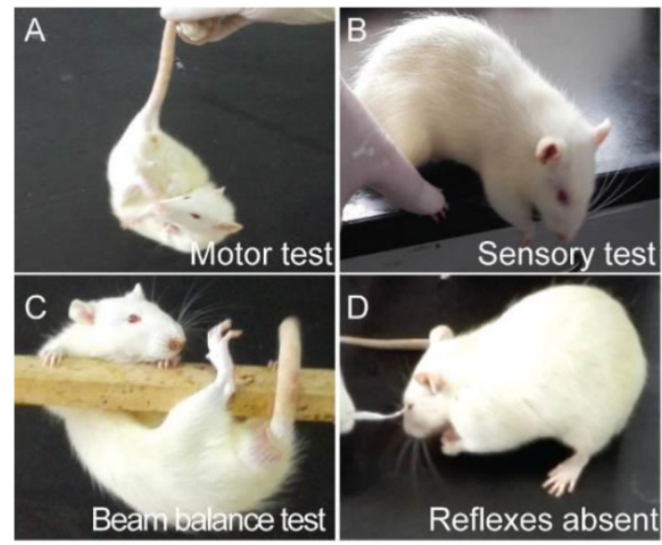

Figure 1. The neurological behavior test on I/R rats (A) Motor test showed the head of the $I / R$ rat moved over $10^{\circ}$ to vertical axis within $30 \mathrm{~s}$; (B) sensory test showed the limb muscle of the I/R rat failed to be stimulated while its paw was pushed against the table edge; (C) beam balance test showed the I/R rat attempted to balance on the beam but fell off; (D) I/R rat was absent of corneal reflex while cornea was touched by cotton.

Table 1. The mNSS scores of $I / R$ rats after grouped before C-P treatment. (Mean=Average \pm SD)

\begin{tabular}{lll}
\hline Group & $n$ & mNSS scores \\
\hline I/R & 18 & $12.68 \pm 0.91$ \\
I/R +C-P65.4 mg/kg & 18 & $13.25 \pm 0.94$ \\
I/R +C-P32.7 mg/kg & 18 & $11.67 \pm 0.79$ \\
I/R +C-P16.4 mg/kg & 18 & $12.55 \pm 0.81$ \\
\hline
\end{tabular}

\section{Behavioral test after C-P treatment}

24 hours later, neuroscore was evaluated by mNSS to observe the effect of C-P on neurological deficiency.

\section{Evaluating the infarct volume by TTC}

6 rats of each group were sacrificed for obtaining fresh brains. Each brain was cut into 7 slices with 2 $\mathrm{mm}$ per slice by Brain Matrices (1 mm 175-300, RWD Lifescience Technology Co., Ltd., Shenzhen, China). Slices were merged into $2 \%$ TTC for $30 \mathrm{~min}$ in $37^{\circ} \mathrm{C}$ and then preserved in $4 \%$ paraformaldehyde for 24 hour. After taking pictures, infract tissue was qualified by IPP software (Image-Pro Plus, Version 6.0., Mediea Cybernetics, Inc.) and presented as: Percentage of Infarct Volume $=$ Infarct Volume/ The Volume of The Whole Brain $\times 100 \%$.

\section{Immunohistochemistry}

6 rats of each group were sacrificed for brain slices of $8 \mu \mathrm{m}$. TUNEL stain was followed by the direction of the kit. Pictures were analyzed by IPP. Then, apoptotic rate $=$ the number of the TUNEL ${ }^{+}$ cells / the total number of cells $\times 100 \%$.

Immunofluorescence was performed as described below. Briefly, slices were blocked by $5 \%$ BSA in $37^{\circ} \mathrm{C}$ for 1 hour, and then respectively incubated with primary anti-bodies of NF200 (1:200), GFAP (1:200) and $\operatorname{vWF}(1: 200)$ in $4^{\circ} \mathrm{C}$ overnight. After washed with PBS for $3 \times 5 \mathrm{~min}$, slices were incubated with the secondary anti-bodies and DAPI in dark. Pictures were captured by a fluorescence microscope (DFC310, Leica, Germany) and then analyzed by IPP. Specifically, the average of fluorescence density $=$ the total value of fluorescence / the number of cells.

\section{ELISA Analysis}

The levels of NO, MDA, LDH and SOD were detected by ELISA. All producers follow the direction of the kit. The absorbance of each sample was detected by Biotek (ELx800, USA) at $490 \mathrm{~nm}$.

\section{Western Blot Analysis for brain tissues}

Following the direction of kits, the nuclear extracts for detecting NF-KB/p65 and the total proteins were extracted from brain tissues, and samples containing 20-30 $\mu \mathrm{g}$ were loaded onto $10 \%$ Tris/Glycine SDS-PAGE gel for electrophoresis. After transferring to PVDF membranes (Millipore), the membranes were blocked in 5\% skim milk for 1 hour. Then, membranes were incubated overnight at $4^{\circ} \mathrm{C}$ with following primary antibodies, anti-GAP-43 antibody $(1: 1,000)$, anti-EPO antibody (1:300), anti-EPOR antibody $(1: 1,000)$, anti-VEGF antibody (1:800), anti-TNF-a antibody (1:1,000), anti-NF-KB / p65 (1:1,000) antibody, anti-IL-6 antibody (1:1,000), anti-IL-1 $\beta$ antibody (1:300) and anti-GAPDH antibody $(1: 10,000)$. Then, they were incubated with peroxidase-conjugated secondary antibodies, and visualized by ECL (Millipore) with Gel Image Analysis System (Tanon-3500R, Shanghai, China). Optical density was analyzed by image analysis software.

\section{Primary cells cultures and immunophenotyp- ing}

The primary cerebral endothelial cells and astrocytes were followed as previous report $[18,19]$. The cultures of primary neurons were performed as described [20] with some improvements. Briefly, cerebral cortexes were departed from brains and cut into sections as small as possible. Then the tissues were incubated with $0.25 \%$ trypsin in $37^{\circ} \mathrm{C}$ for about $10 \mathrm{~min}$ for acquiring single cell suspension. The cells, then, were cultured in FBS-free DMEM/F12 medium containing 2\% B27.

For the immunophenotyping of the three types of primary cells, cell markers of MAP-2, vWF, and GFAP were selected for neurons, endothelial cells, and astrocytes respectively. In parallel, the rate of cellular purity was analyzed by the formula: the rate of purity $=$ the number of cells with $\mathrm{DAPI}^{+}$and marker ${ }^{+}$/ the number of DAPI ${ }^{+}$. 


\section{Establishment of NVU in vitro}

The NVU model was established according to our previous report [10]. Briefly, as shown in Figure 2, after the neurons has grown in a 6-well culture plate with a density of $0.5 \times 10^{5}$ cells $/ \mathrm{cm}^{2}$ for 2 days, the purified astrocytes with $1.5 \times 10^{5}$ cells $/ \mathrm{cm}^{2}$ were seeded on the outer side of insert membrane which side faces the bottom of the well. After $4 \mathrm{~h}$ for astrocytes adhering, the insert was placed into the well with neurons. 2 days later, BMECs $\left(1.0 \times 10^{5}\right.$ cells $\left./ \mathrm{cm}^{2}\right)$ were seeded in the inner side of the insert membrane. After co-cultured for 3-5 days, the NVU model was prepared for following experiments.

\section{Establishment of OGD/R damaging NVU in vitro}

Experiments were conducted as our previous descriptions with some improvements [10]. Briefly, the prepared NVUs were cultured in conditional medium (glucose-free, $98.5 \mathrm{mM} \mathrm{NaCl}, 10.0 \mathrm{mM} \mathrm{KCl}, 1.2$ $\mathrm{mM} \mathrm{MgSO}_{4}, 0.9 \mathrm{Mm} \mathrm{Na}_{2} \mathrm{HPO}_{4}, 6.0 \mathrm{mM} \mathrm{NaHCO}, 1.8$ $\mathrm{mM} \mathrm{CaCl}_{2}, 40 \mathrm{mM}$ Sodium lactate and $20 \mathrm{mM}$ HEPES with pH6.8) and placed in an anaerobic incubator (BINDER CB150, Germany) with condition of $5 \%$ $\mathrm{CO}_{2}, 0.2 \% \mathrm{O}_{2}$, and $37^{\circ} \mathrm{C}$ for $2 \mathrm{~h}$. Then cultures were switched to completely normal conditions for $22 \mathrm{~h}$. The successfully damaged NVUs were of phenotype of contracted cells and typically decreased TEER $(P<$ $0.05)$.

\section{Experimental groups and treatment in vitro}

NVUs were randomly divided into 5 groups $(n=6)$ of normal, OGD/R and three doses of C-P $(49.00$ $\mu \mathrm{g} / \mathrm{ml}, 24.50 \mu \mathrm{g} / \mathrm{ml}$ and $12.25 \mu \mathrm{g} / \mathrm{ml}$ ). C-P treatment was performed when the cultures were switched to

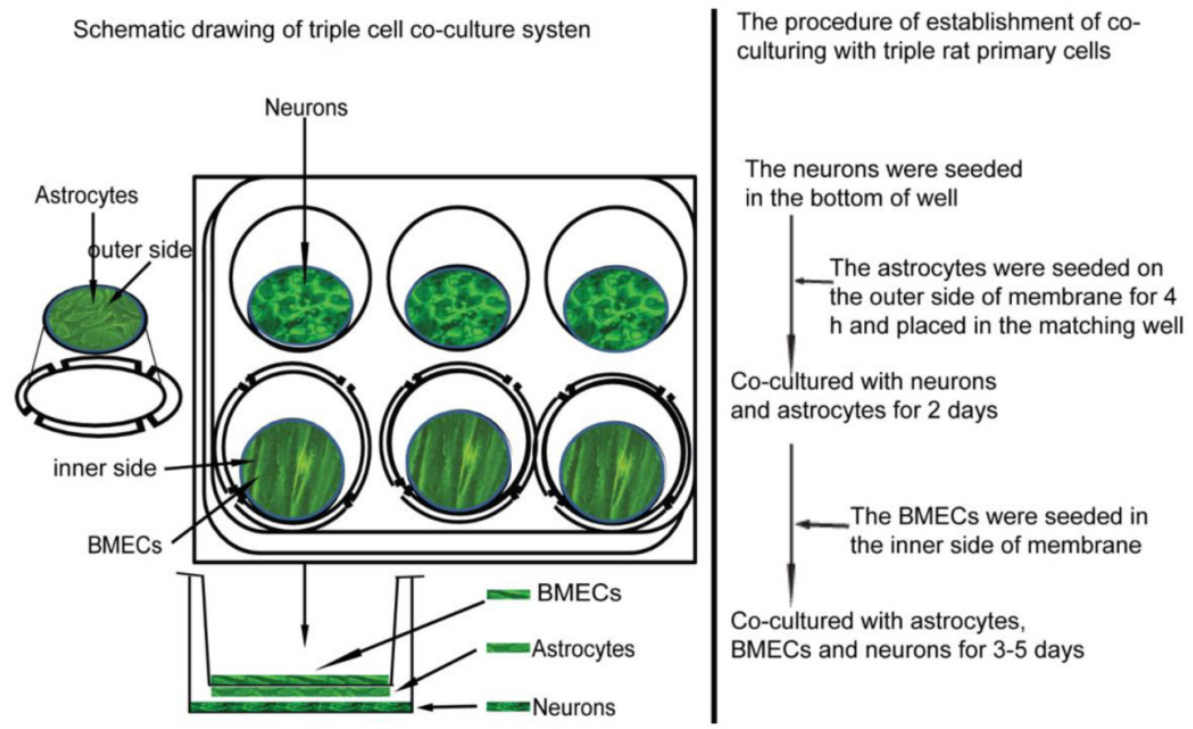

Figure 2. The illustration of constructing NVU in vitro. normal conditions.

\section{Detection of cellular survival and morphology}

After OGD/R, the images of astrocytes, neurons and BMECs in each group of in vitro NVU models were captured by an inverted phase contrast microscope (Carl Zeiss IX 71, Germany). Then, the axonal length of neurons in each group was analyzed by IPP software. After digestion with trypsin, the number of survival astrocytes and BMECs were counted by trypan blue.

\section{Permeability measurement of NVU by TEER and SF}

TEER values of NVUs were measured by an epithelial-volt-ohm resistance meter (ERS-2, Millipore, USA) according to its instructions and previous report [21]. The TEER value of the well without cells was regarded as background. The final TEER value = (sample TEER value - background TEER value) $\times$ the area of membrane. The values were expressed as $\Omega \cdot \mathrm{cm}^{2}$.

The flux of SF across the endothelial cells was performed as previously described [22]. Briefly, cultures were switched to $1 \mathrm{ml}$ DMEM-F12 medium containing a final concentration of $10 \mu \mathrm{g} / \mathrm{ml} \mathrm{SF}$. After incubated for 2 hours, $100 \mu \mathrm{l}$ medium under the transwell membrane was taken out. The absorbance was measured by fluorospectrophotometer (HITACHI F-4500, Japan, emission wavelength: 525 $\mathrm{nm}$; excitation wavelength: $440 \mathrm{~nm}$ ).

\section{ELISA}

Endothelial cells in the inner side of membrane were lysed on ice for 10 min by RIPA (Beyotime Institute of Biotechnology, Haimen, Jiangsu, China) after astrocytes had been scraped off. After being centrifuged $\left(4^{\circ} \mathrm{C}, 13,000 \quad(\times \mathrm{g})\right.$ for $10 \mathrm{~min})$, the supernatants were collected to test the $y$-GTP activity. The supernatants of the NVUs were collected for the test of NO, MDA, LDH, and SOD. During the whole experiment, PMSF was used to protect proteins from degradation. All the experimental procedures follow the direction of the kit.

\section{Western Blot Analysis for NVU in vitro}

Cells in the NVUs were respectively scraped down and lysed on ice for $10 \mathrm{~min}$. After 
centrifugation $\left(13,000(\times \mathrm{g}), 4^{\circ} \mathrm{C}\right)$, the resulting supernatant was saved as the cytoplasmic extract sample and the nuclear pellet was prepared for nuclear extract sample. Samples were used for measuring the expressions of GAP43, EPOR, Claudin-5 and NF-KB/p65, respectively. The lyophilized cultures supernatants were used to measure the secreted proteins including VEGF、EPO、TNF- $\alpha$, IL-1 $\beta$ and IL-6. All of these proteins were measured by Western Blot. Specific procedures were followed as previous descriptions in this research.

\section{Statistical analysis}

All the results were repeated at least three times. All pictures were analyzed by IPP software. Data were statistically analyzed by ANOVA (SPSS 17.0). Results were expressed as mean \pm SD. $P<0.05$ was regarded to be statistically significant.

\section{Results}

\section{Quality control of C-P}

As shown in Figure 3, the retention times of catalpol and puerarin in C-P (C) were consistent with the standards of catalpol (A) and puerarin (B). This suggests that C-P contained catalpol and puerarin.

\section{C-P ameliorated neurological deficiency in I/R rats}

The successful establishment of I/R rats were of significantly increased neurological deficiency compared with the normal $(P<0.01)$. The average mNSS scores of C-P groups including doses of $65.4 \mathrm{mg} / \mathrm{kg}$, $32.7 \mathrm{mg} / \mathrm{kg}$, and $16.4 \mathrm{mg} / \mathrm{kg}$ were 6.88 8.17, which were significantly decreased compared with the average mNSS score of $\mathrm{I} / \mathrm{R}$ rats $(P<0.01)$, which is 11.65 . (Figure 4)
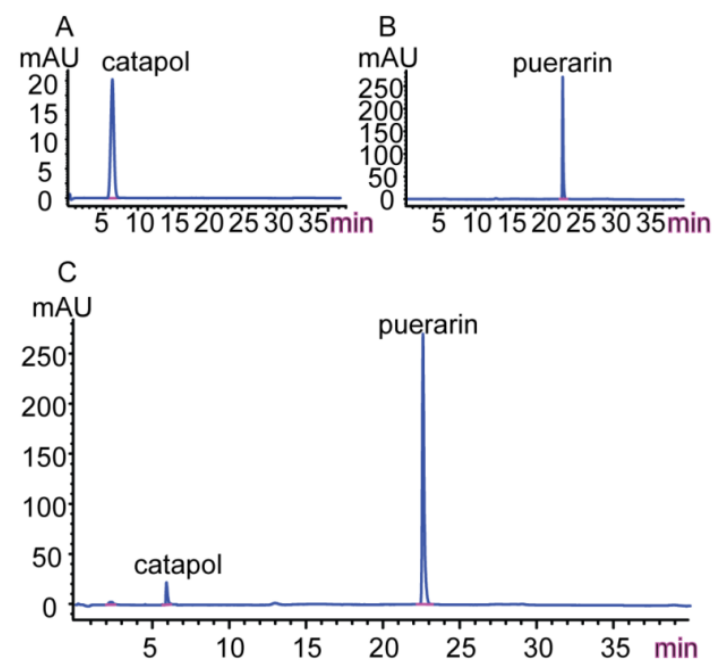

Figure 3. High-performance liquid chromatogram of C-P (A) Catalpol standard; (B) Puerarin standard; (C) C-P.

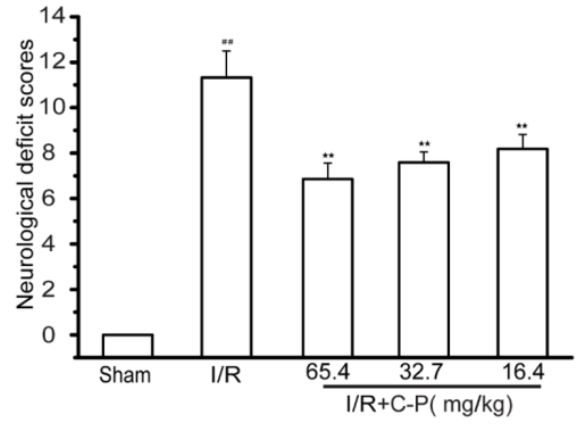

Figure 4. C-P ameliorated the $\mathbf{m N S S}$ scores of I/R rats. (Mean $\pm S D, n=18$ ), \#means $P<0.01$ (I/R versus sham); ${ }^{\star \star}$ means $P<0.01$ (C-P versus I/R)

A

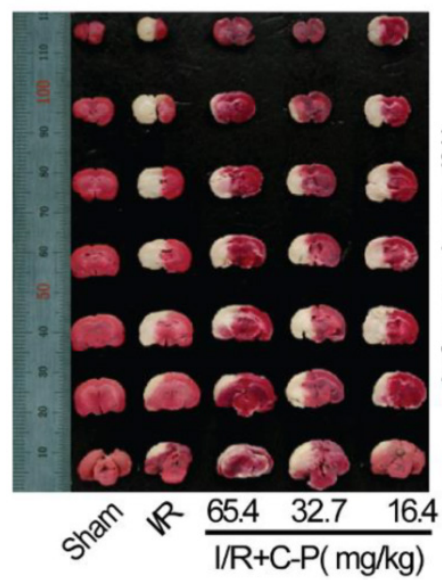

Figure 5. C-P decreased the infarct volume (A) Infarct tissues were stained by TTC. (B)The percentages of the infarct volume in I/R and C-P groups indicated C-P decreased the infarct volume significantly (values represent mean $\pm S D, n=6$ ); \#\# means $P<0.01$ (I/R versus sham); ${ }^{\star}$ means $P<0.05$, ${ }^{\star \star}$ means $P<0.01$ (C-P versus I/R).

\section{C-P reduced the infarct volume}

The infarct tissues were typically expressed as white after stained by TTC (Figure $5 \mathrm{~A}$ ). The average rate of infarct volume to whole brain in C-P groups $(65.4 \mathrm{mg} / \mathrm{kg} 、 32.7 \mathrm{mg} / \mathrm{kg}$ and $16.4 \mathrm{mg} / \mathrm{kg}$ ) (Figure 5 B) were $14.79 \%, 17.78 \%$, and $28.72 \%$, all of which were significantly decreased compared with $\mathrm{I} / \mathrm{R}$ rats $(33.7 \%)(P<0.01, P<0.05)$.

\section{C-P protected cerebral cells from apoptosis in ischemic area}

In sham group, only about $5.98 \%$ cerebral cells were of apoptotic phenotype (stained by TUNEL). This type of cells was remarkably increased to $53.28 \%$ in I/ $\mathrm{R}$ rats $(P<0.01)$. With treatment of $\mathrm{C}-\mathrm{P}$ with the three doses, apoptotic cells were significantly decreased to $14.79 \%, 17.78 \%$, and $28.72 \%$ respectively $(P<0.01, P<0.05)$. (Figure 6)

\section{C-P improved the growth of the main cells of NVU in ischemic area}

vWF, GFAP, and NF200 staining were respec- 
tively used to observe the morphologies of vessels, astrocytes, and neurons in infarct area. As showed in Figure 7 B, vessels in I/R group were fragmental instead of an intact one as showed in Figure 7 A. Also, obviously shortened astrocytes processes (Figure 7 G) and disappeared axons of neurons were observed simultaneously (Figure 7 G, L). For quantity analysis, the average intensity of fluorescence of each group was calculated. The data were in accordance with the morphological observation $(P<0.01)$. With the intervention of C-P with the three doses, only the doses of $65.4 \mathrm{mg} / \mathrm{kg}$ and $32.7 \mathrm{mg} / \mathrm{kg}$ weakened these damage manifestations $(P<0.01)$ except for the dose of 16.4 $\mathrm{mg} / \mathrm{kg}$ (Figure 7 C-E, H-J, M-O).

\section{C-P reduced the oxidative stress injury in I/R rats}

Figure 8 shows that MDA, LDH, and NO were increased and LDH was decreased significantly in brain tissue in I/ R group $(P<0.01)$. C-P turned such an adverse trend into a favorable one. $65.4 \mathrm{mg} / \mathrm{kg}$ and $32.7 \mathrm{mg} / \mathrm{kg}$ C-P reduced the levels of MDA, LDH, and $\mathrm{NO}$ and enhanced the level of SOD compared with $\mathrm{I} / \mathrm{R}$ rats $(P<0.01)$. However, $16.4 \mathrm{mg} / \mathrm{kg}$ C-P signifi- cantly increased MDA, LDH, and NO $(P<0.05, P<0.01)$ but not SOD $(P=0.12)$.

\section{C-P inhibited the inflammation in I/R rats}

Figure 9 shows that NF-kB/p65, TNF- $\alpha$, IL-1 $\beta$ and IL-6 were upregulated in I/R rats $(P<0.01)$. In addition, $65.4 \mathrm{mg} / \mathrm{kg}, 32.7 \mathrm{mg} / \mathrm{kg}$ and $16.4 \mathrm{mg} / \mathrm{kg}$ C-P decreased all inflammatory factors to various extents $(P<0.01)$.

\section{C-P enhanced the favorable factors in $\mathbf{I} / \mathbf{R}$ rats}

For rats suffered from I/R, favorable factors as EPO, EPOR, VEGF, and GAP-43 were drastically decreased in brains' tissues $(P<0.01)$. After treatment of C-P with doses of $65.4 \mathrm{ma} / \mathrm{kg}, 32.7 \mathrm{mg} / \mathrm{kg}$, and 16.4 $\mathrm{mg} / \mathrm{kg}$, only the doses of the higher two enhanced all of these factors and the lowest one only increased EPOR $(P<0.05, P<0.01)$. (Figure 10)

\section{Immunophenotyping controlled the qualities of the cell types and purities used in in vitro NVU models}

By MAP-2, vWF, and GFAP staining, the immunophenotyping of neurons, endothelial cells and astrocytes were confirmed, and cellular purities were all beyond 95\%. (Figure 11)

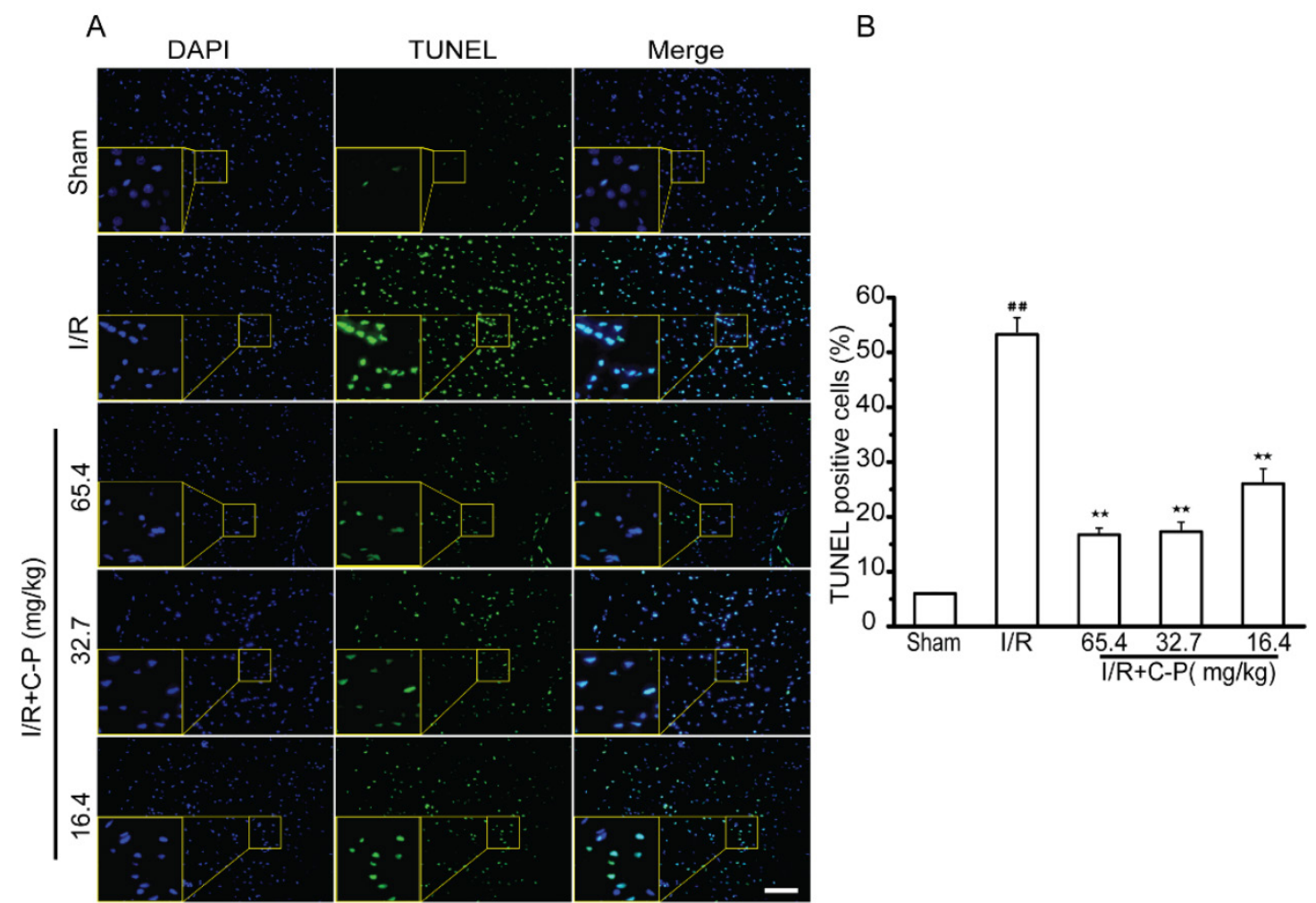

Figure 6. C-P decreased apoptotic cells in infarct region $(A, B) B y$ TUNEL stain, $C-P$ was proved to protect cerebral cells from apoptosis $(B a r=100 \mu m)($ values represent mean $\pm S D, n=6$ ); ${ }^{\#}$ means $P<0.01$ (I/R versus sham); ${ }^{\star \star}$ means $P<0.01(C-P$ versus $\mathrm{I} / \mathrm{R})$. 

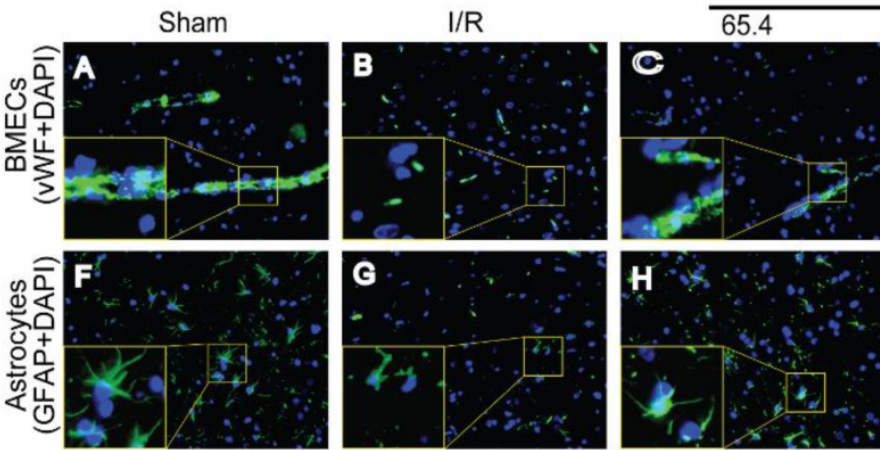

$\mathrm{l} / \mathrm{R}+\mathrm{C}-\mathrm{P}(\mathrm{mg} / \mathrm{kg})$
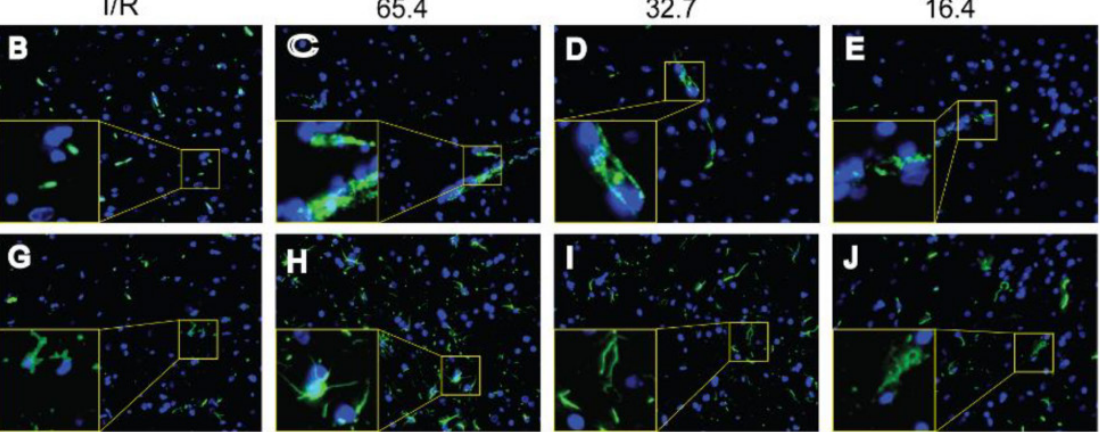

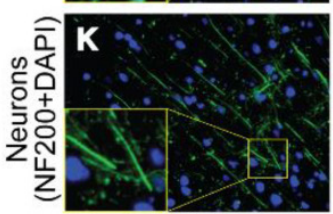

$\mathrm{P}$
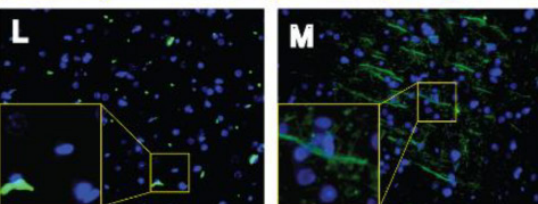

Q
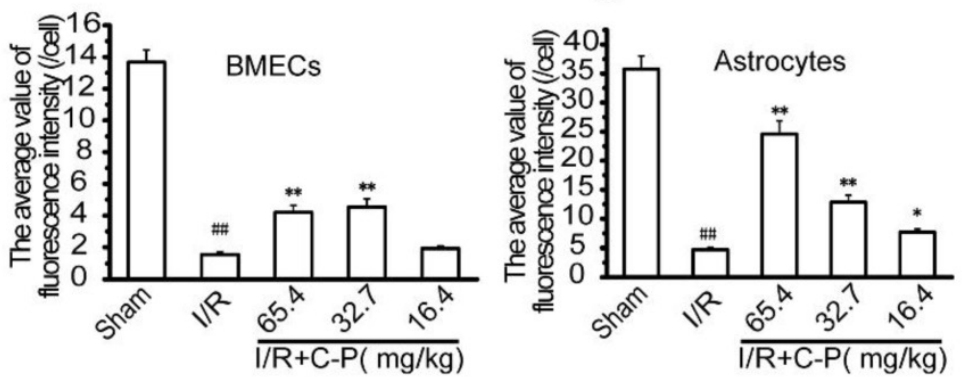

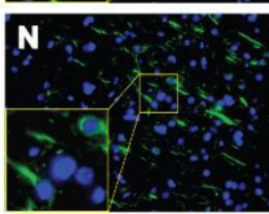

$\mathrm{R}$
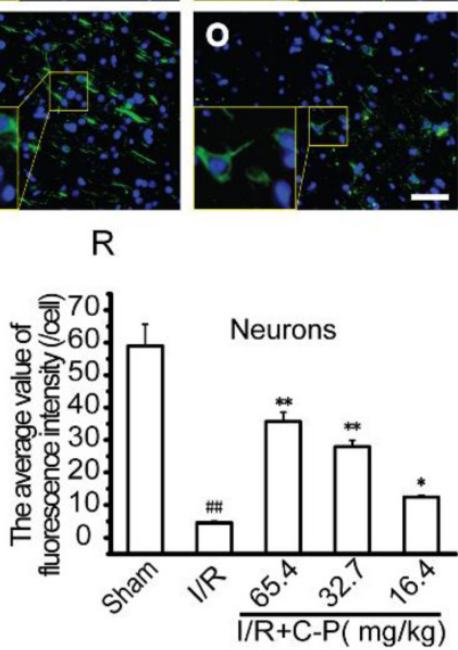

Figure 7. C-P improved the morphologies of the three main types of cerebral cells in infarct region (A-E) The morphologies of vasculatures observed by immunofluorescence of vWF and DAPI. (F-J) The morphologies of astrocytes were observed by immunofluorescence of GFAP and DAPI. (K-O) The morphologies of neurons were observed by immunofluorescence of NF200 and DAPI. (P-R) The average of fluorescence densities of vWF, GFAP, and NF200 in each group, which suggests that C-P improved the morphologies of the three types of cells $(B a r=50 \mu \mathrm{m})$ (values represent mean $\pm \mathrm{SD}, n=6)$; ${ }^{\#}$ means $P<0.01\left(\mathrm{I} / \mathrm{R}\right.$ versus sham); ${ }^{\star}$ means $P<0.05,{ }^{\star}$ means $P<0.01(C-P$ versus $\mathrm{I} / \mathrm{R}$ ).

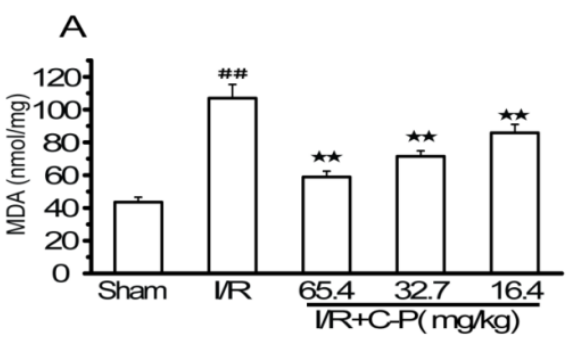

C

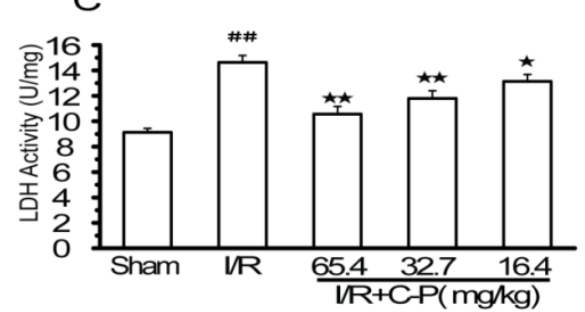

B

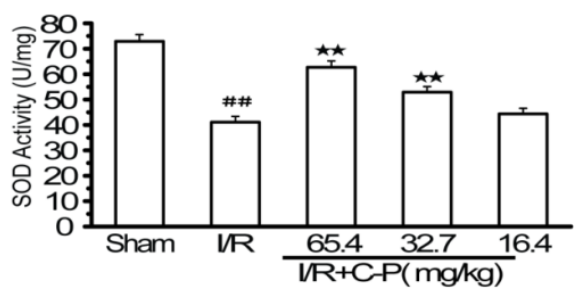

D

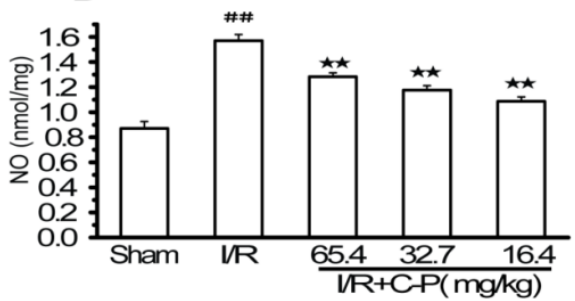

Figure 8. C-P protected brains from oxidative stress injury in I/R rats (A-D) The levels of MDA, SOD, LDH, and NO in each group were tested by ELISSA. Results suggested $C$-P had an effect of anti-oxidative stress injury in vivo (values represent mean $\pm S D, n=6)$; ${ }^{\#}$ means $P<0.01$ (I/R versus sham); ${ }^{\star}$ means $P<0.05,{ }^{\star \star}$ means $P<0.01(C-P$ versus $\mathrm{I} / \mathrm{R})$. 
A
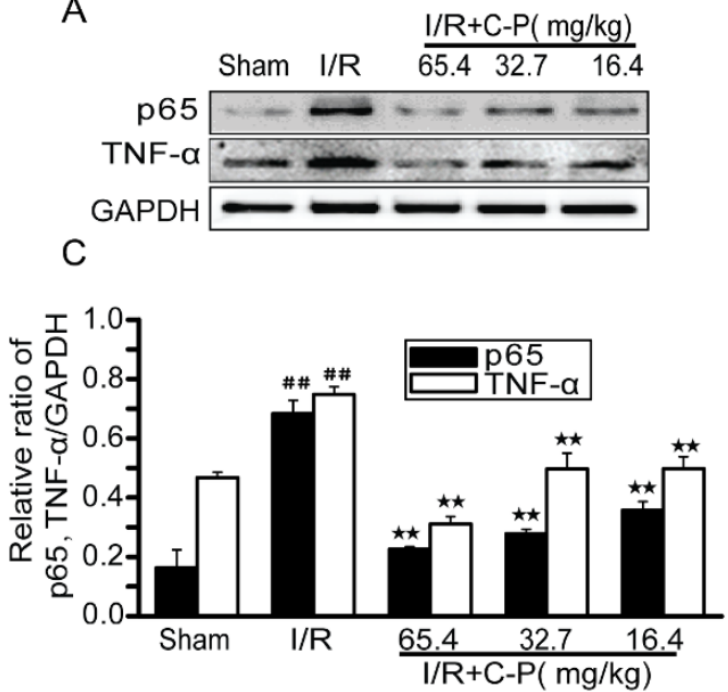

B

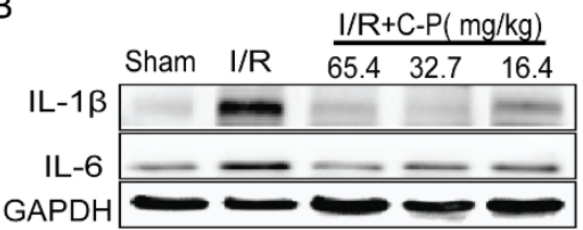

$\mathrm{D}$

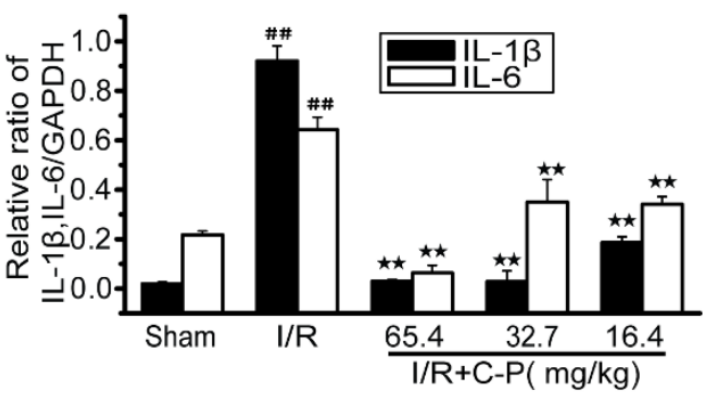

Figure 9. C-P protected brains from inflammation in I/R rats $(A, B)$ The expressions of TNF- $\alpha, N F-K B / p 65$, IL- 6 and IL-1 $\beta$ in each groups were tested by Western Blot. $(C, D)$ The semiquantitative analyses for these proteins in all groups suggested C-P had an effect of anti-inflammation in vivo. (values represent mean \pm SD, $n=6$ ); ${ }^{\prime \prime}$ means $P$ $<0.01$ (I/R versus sham); ${ }^{\star \star}$ means $P<0.01$ (C-P versus I/R).

A

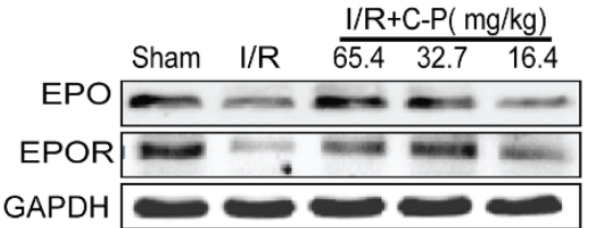

C

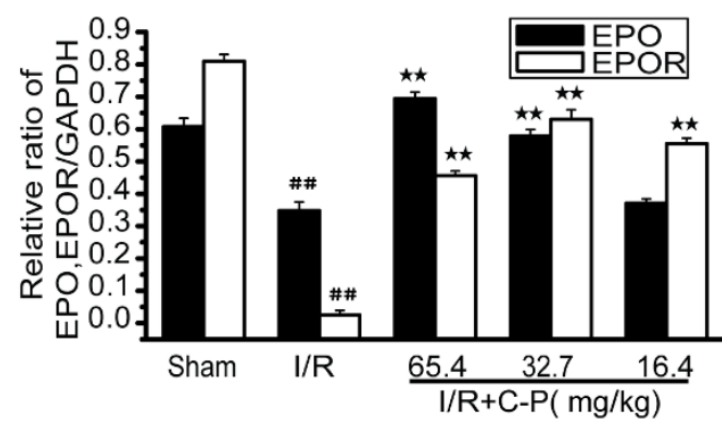

B

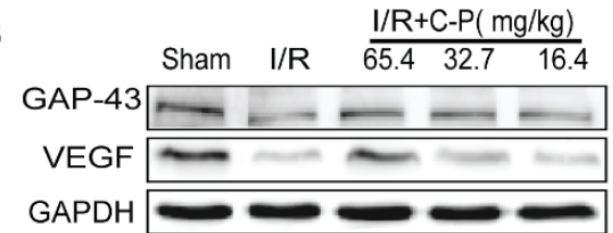

D

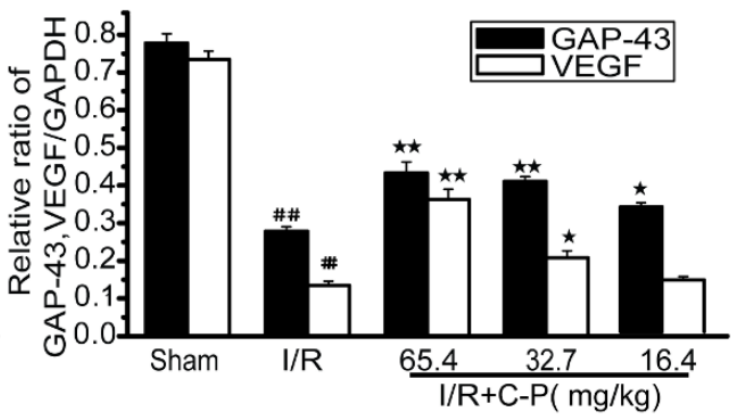

Figure 10. C-P promoted the expressions of favorable factors in I/R rats (A, B) The expressions of EPO, EPOR, GAP-43, and VEGF in each group were tested by Western Blot. (C, D) The semiquantitative analyses suggested C-P significantly improved these factors in vivo. (values represent mean \pm SD, $n=6$ ); $\#$ means $P<0.01$ (I/R versus sham); ${ }^{\star}$ means $P<0.05,{ }^{\star \star}$ means $P<0.01$ ( $C-P$ versus $I / R$ ).

\section{C-P improved the cellular survival and the morphologies of the three types of cells in OGD/R-damaged NVU}

As shown in Figure 12, the three types of cells were of typical damage manifestations after OGD/R. But with treatment of C-P with doses of $49 \mu \mathrm{g} / \mathrm{mL}$, $24.5 \mu \mathrm{g} / \mathrm{mL}$, and $12.25 \mu \mathrm{g} / \mathrm{mL}$, these manifestations were all weakened, the axonal length of neurons and the numbers of BMECs and astrocytes were increased.

\section{C-P protected the BBB of NVU from OGD/R}

TEER, $\gamma$-GTP, and Claudin-5 were selected to evaluate the permeability of BBB in in vitro NVU models. After OGD/R, all of these indexes were significantly decreased, which suggests that the BBB was damaged $(P<0.01)$. Meanwhile, this damage was confirmed by the increased absorbency of SF after $\mathrm{OGD} / \mathrm{R}(P<0.01)$. With treatment of C-P with doses of $49 \mu \mathrm{g} / \mathrm{mL}, 24.5 \mu \mathrm{g} / \mathrm{mL}$, and $12.25 \mu \mathrm{g} / \mathrm{mL}$, all the indexes were turned into a favorable trend to different degrees $(P<0.05, P<0.01$, Figure 13$)$. 

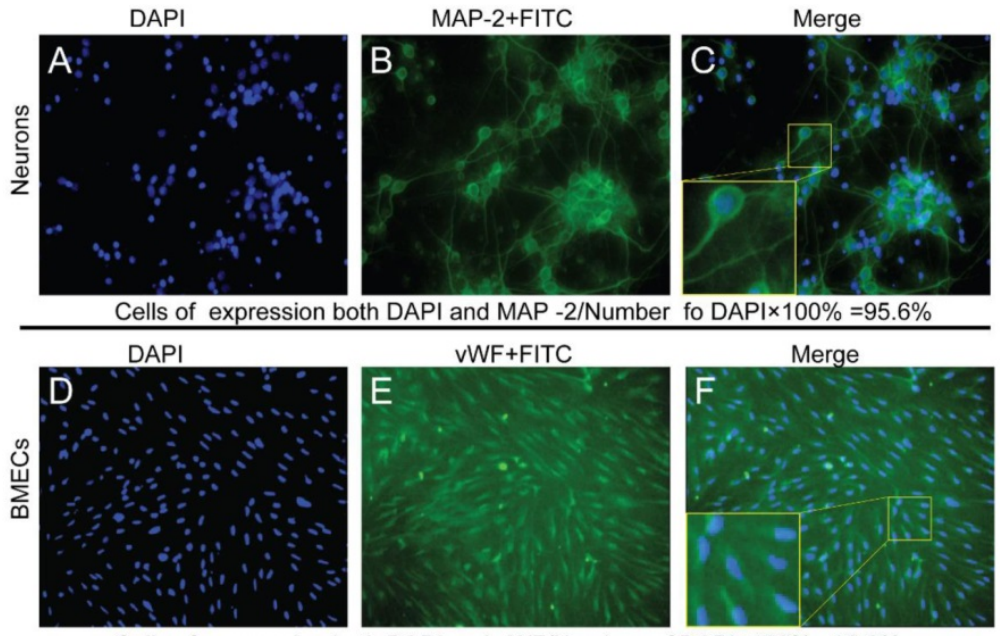

Cells of expression both DAPI and vWF/Number of DAPI $\times 100 \%=99.2 \%$

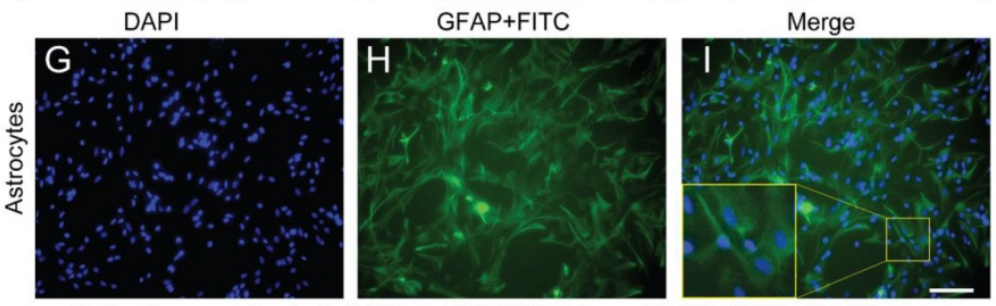

Cells of expression both DAPI and GFAP/Number of DAPI $\times 100 \%=97.4 \%$

Figuew 11. Immunophenotyping controlled the qualities of the neurons, endothelial cells, and astrocytes used in NVUs (A-C) Immunophenotyping of neurons were identified by MAP-2, and cell purity was beyond 95\%.(D-E) Immunophenotyping of endothelial cells were identified by vWF, and cell purity was beyond $99 \%$. (G-F) Immunophenotyping of astrocytes were identified by GFAP, and cell purity was beyond $97 \%(\mathrm{Bar}=50 \mu \mathrm{m})$.

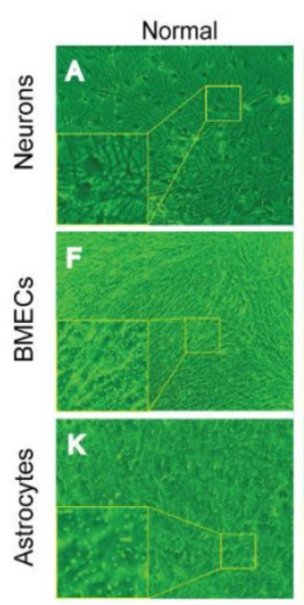

OGD/R
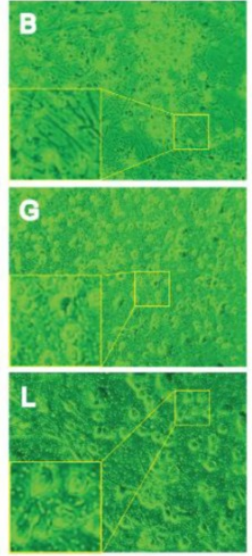

$\mathrm{Q}$
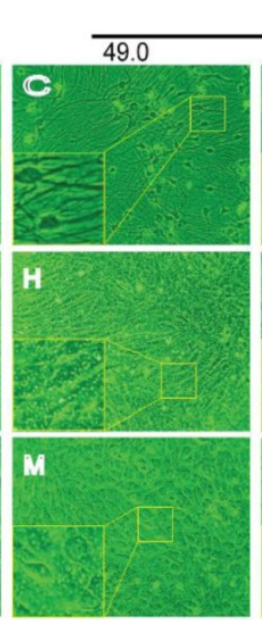

$\mathrm{OGD} / \mathrm{R}+\mathrm{C}-\mathrm{P}(\mu \mathrm{g} / \mathrm{mL})$
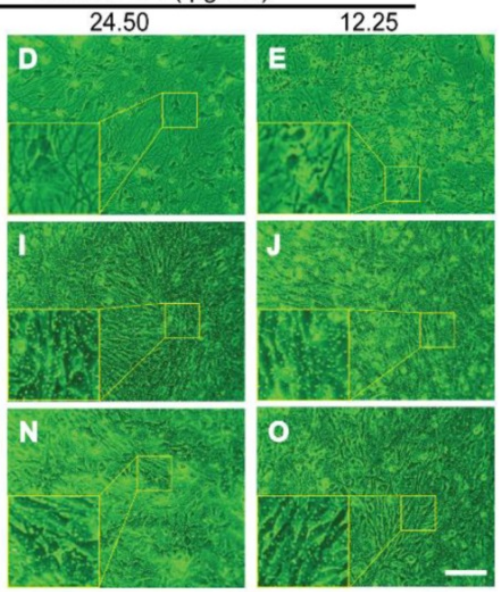

$\mathrm{R}$
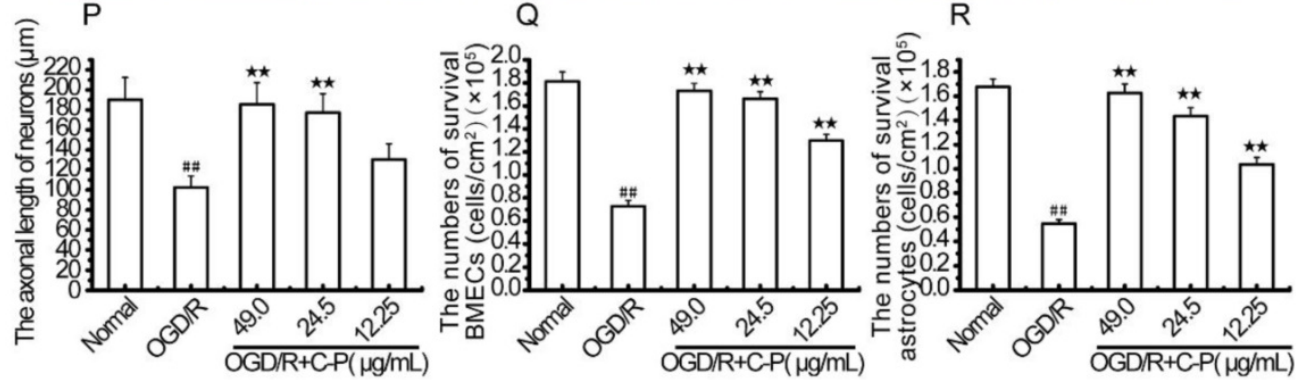

Figure 12. C-P improved the cellular survival and the morphologies of the three types of cells in NVU models (A, F, K) Pictures show the morphologies of health neurons, endothelial cells, and astrocytes. (A) The bodies of neurons were extended, and axons formed a compact network. (F) Healthy endothelial cells touched with each other to form a compact monolayer. (K) Normal astrocytes had an extended body and tightly touched with each other. (B, G, L) Pictures show the morphologies of the three types of cells after OGD/R. (B) Neurons contracted their bodies and axons resulting in a sparse network. (G, L) Endothelial cells and astrocytes contracted significantly and were

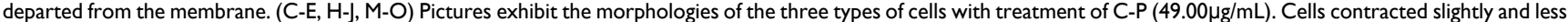
of them departed from the membrane than OGD/R. (P-R) The axonal length of neurons and the numbers of BMECs and astrocytes in each group were quantitatively analyzed, which suggest that C-P improved the cellular survival and the morphologies of the three types of cells $($ Bar $=100 \mu \mathrm{m})($ values represent mean \pm SD, $n=6)$; ${ }^{\prime}$ means $P<0.01$ (OGD/R versus normal); ${ }^{\star \star}$ means $P<0.01$ (C-P versus OGD/R). 


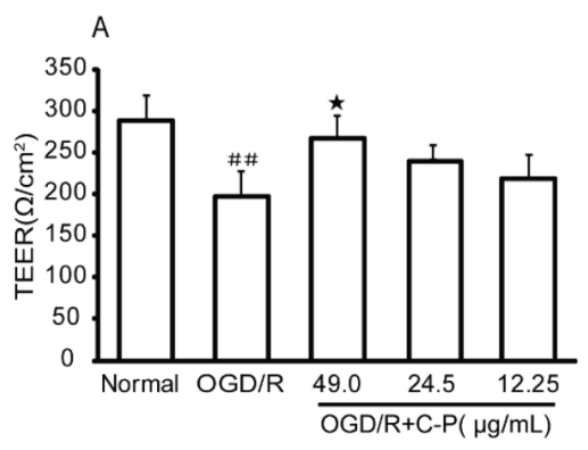

B

C

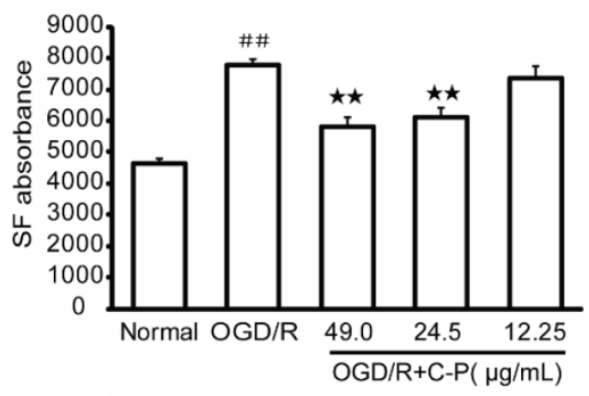

$\mathrm{D}$

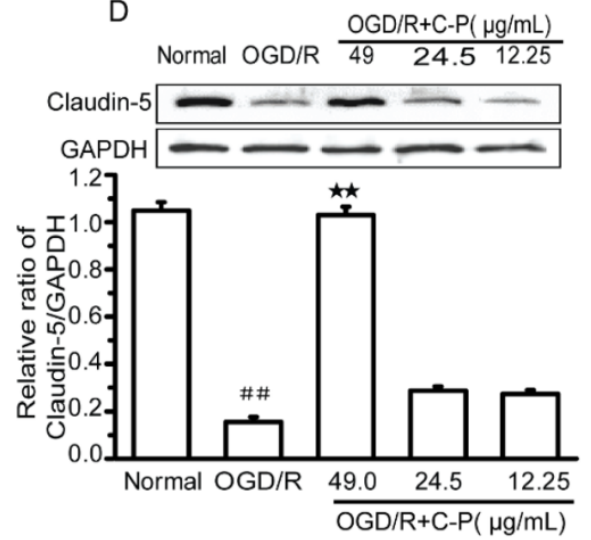

Figure 13. C-P protected the BBB of the NVU models (A) The TEER of the NVU in each group showed C-P protected BBB with the dose of $49.00 \mu$ g/mL. (B, C) SF absorbance and $\gamma$-GTP activity showed the doses of $49.00 \mu \mathrm{g} / \mathrm{mL}$ and $24.5 \mu \mathrm{g} / \mathrm{mL}$ had decreased the permeability of BBB after OGD/R. (D) Western Blot showed that C-P strengthened Claudin-5 with the dose of $49.00 \mu \mathrm{g} / \mathrm{mL}$ (values represent mean $\pm \mathrm{SD}, n=6)$; ${ }^{\#}$ means $P<0.01\left(\mathrm{OGD} / \mathrm{R}\right.$ versus normal); ${ }^{\star}$ means $P<0.05,{ }^{\star \star}$ means $P<0.01(C-P$ versus OGD/R).

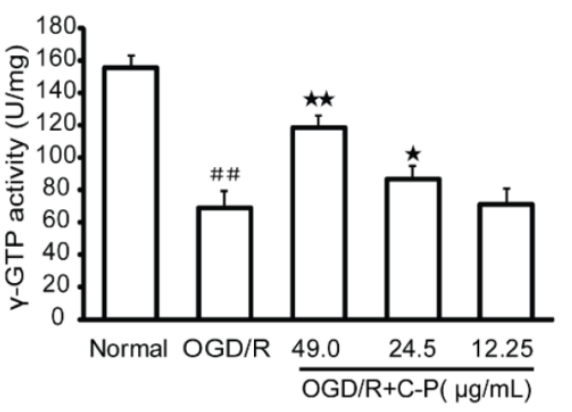

B
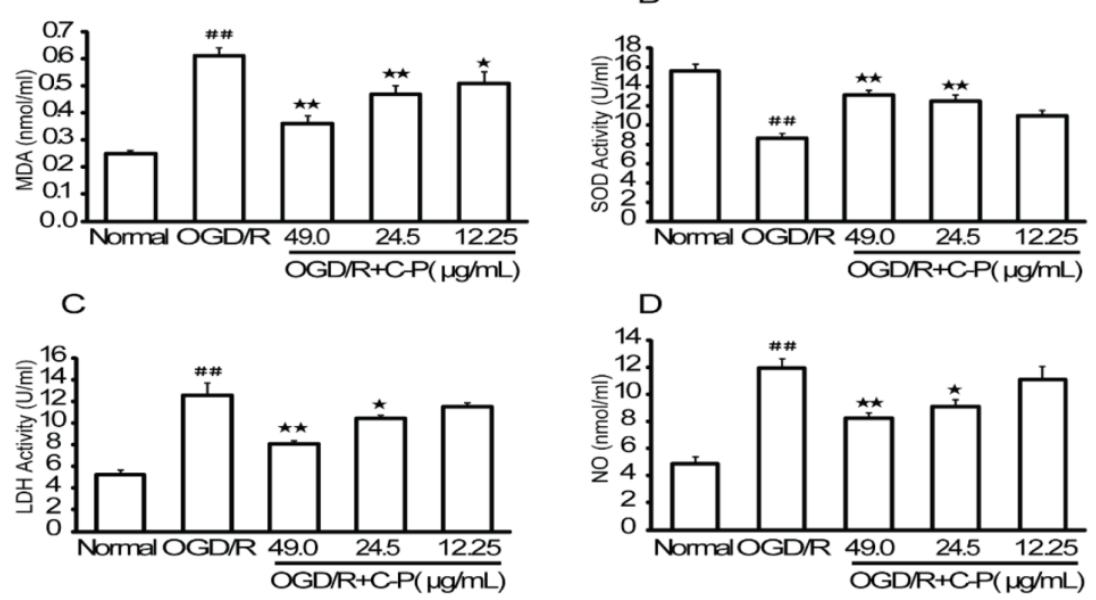

Figure 14. C-P protected NVU models from oxidative stress injury in vitro (A-D) Levels of MDA, SOD, LDH, and NO in each group were tested by ELISSA. Results suggested $C$-P had an effect of anti-oxidative stress injury in vitro (values represent mean $\pm \mathrm{SD}, n=6)$; ${ }^{\#}$ means $P<0.01\left(\mathrm{OGD} / \mathrm{R}\right.$ versus sham); ${ }^{\star}$ means $P<0.05,{ }^{\star \star}$ means $P$ $<0.01$ (C-P versus OGD/R).

\section{C-P reduced the oxidative stress injury in OGD/R-damaged NVU}

Data obtained in this section (Figure 14) were similar to that of in vivo section (Figure. 8). Briefly, MDA, LDH, and NO were increased and LDH was decreased significantly in OGD/R group $(P<0.01)$. C-P with doses of $49 \mu \mathrm{g} / \mathrm{mL}$ and $24.5 \mu \mathrm{g} / \mathrm{mL}$ reduced oxidative stress by performing on these factors $(P<$ $0.01, P<0.05)$, but the dose of $12.25 \mu \mathrm{g} / \mathrm{mL}$ decreased MDA only $(P<0.05)$.

\section{$C-P$ inhibited the over-activated inflammation in OGD/R-damaged NVU}

Figure 15 shows NF-kB/p65, TNF- $\alpha$, IL-1 $\beta$ and IL-6 were over-expressed $(P<0.01)$. These results are 
consistent with those in vivo ones (Figure 9) and suggest that inflammation was over-activated in OGD/R group. C-P with doses of $49 \mu \mathrm{g} / \mathrm{mL}$ and $24.5 \mu \mathrm{g} / \mathrm{mL}$ decreased all of these factors to different degrees $(P<0.05, P<0.01)$. However, the dose of $12.25 \mu \mathrm{g} / \mathrm{mL}$ only decreased TNF- $\alpha$ and NF-kB/ p65 $(P<0.01)$.

\section{C-P up-regulated some favorable factors in OGD/R-damaged NVU}

Figure 16 shows that EPO, EPOR, VEGF and GAP-43 were drastically decreased in OGD/R-damaged NVU $(P<0.01)$ and significantly increased by all doses of $\mathrm{C}-\mathrm{P}(P<0.01)$. These results are consistent with the data in in vivo shown in Figure 10.

A

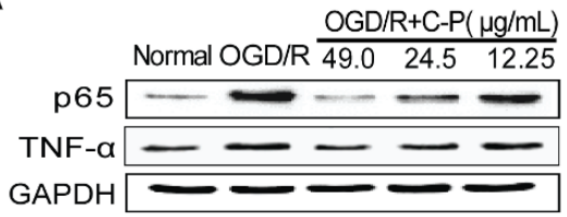

C

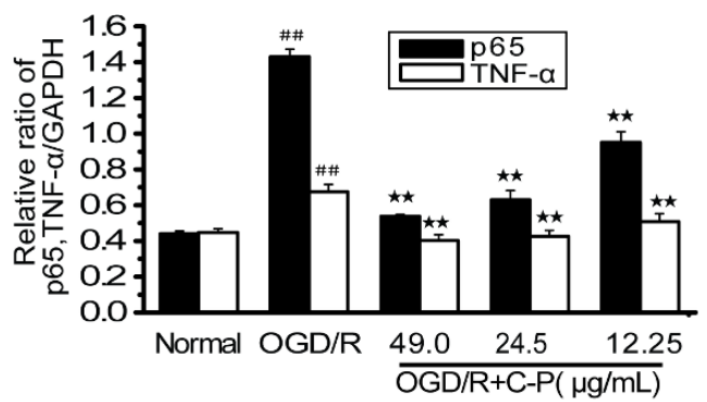

\section{Discussions}

\section{Protecting NVU is the potentiality of treating brain stroke}

The damage of brain stroke is not only involved with neurons but also with gliocytes and microvessels $[7,23,24]$. Damaged cells can spread the damage to their surrounding cells via cellular interactions. After stroke, cerebral cells suffer from a series of pathologies as dysfunctional energy metabolism, excitatory amino acids, inflammation, oxidative stress and apoptosis [7-9].

B

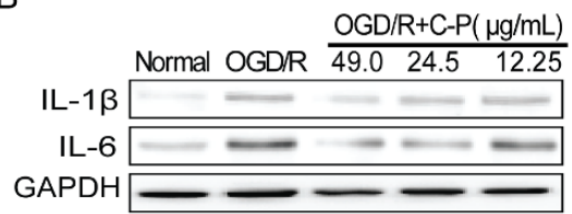

D

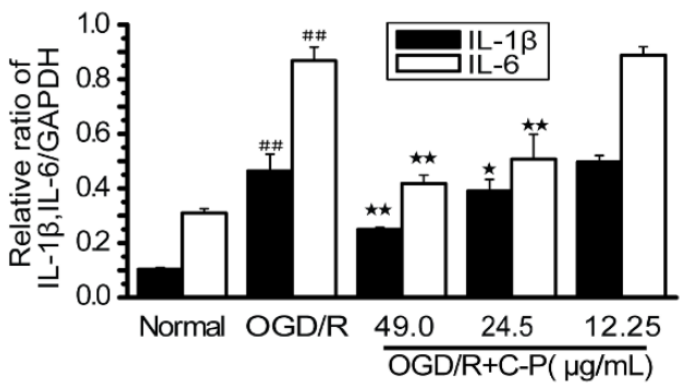

Figure 15. C-P protected NVU models from inflammation in vitro (A, B) The expressions of TNF- $\alpha, N F-K B / p 65$, IL-6 and IL-1 $\beta$ in each group were tested by Western Blot. (C, D) Semiquantitative analyses for these proteins in all groups suggested $C-P$ had an effect of anti-inflammation in vitro (values represent mean \pm SD, $n=6$ ); $\#$ means $P$ $<0.01$ (OGD/R versus sham); ${ }^{\star}$ means $P<0.05,{ }^{\star \star}$ means $P<0.01$ (C-P versus OGD/R).

A

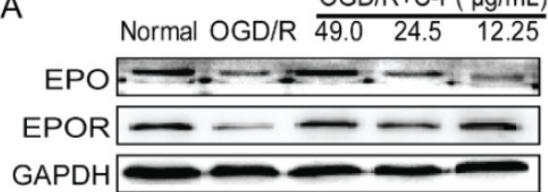

C

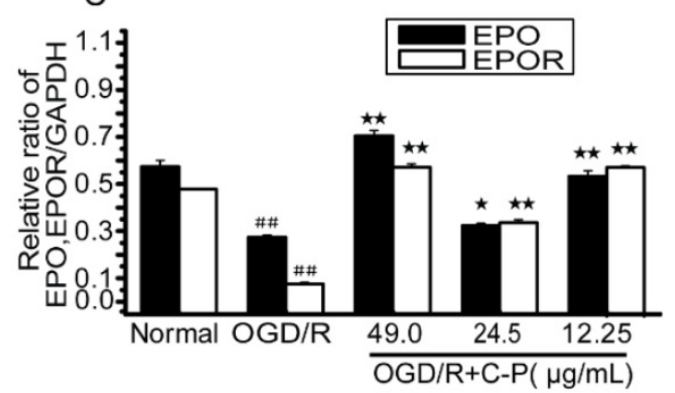

B Normal OGD/R $\frac{\mathrm{OGD} / \mathrm{R}+\mathrm{C}-\mathrm{P}(\mu \mathrm{g} / \mathrm{mL})}{49.0 \quad 24.5 \quad 12.25}$

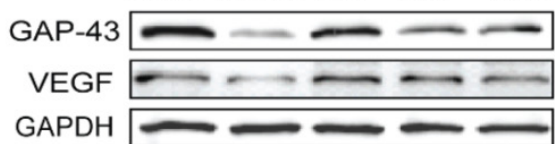

D

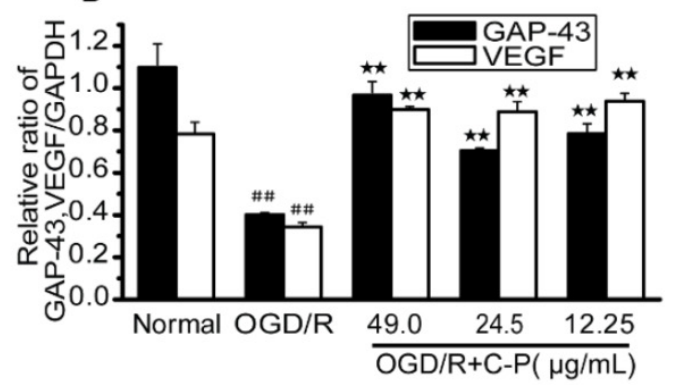

Figure 16. C-P promoted the expressions of favorable factors in vitro (A, B) The expressions of EPO, EPOR, GAP-43 and VEGF in each group were tested by Western Blot. (C, D) Semiquantitative analyses suggested C-P significantly improved these factors in vitro (values represent mean \pm SD, $n=6$ ); ${ }^{\prime \prime}$ means $P<0.01\left(O G D / R\right.$ versus sham); ${ }^{\star}$ means $P<0.05,{ }^{\star \star}$ means $P<0.01$ (C-P versus OGD/R). 
Therefore, treatment targeting to one type of cells or pathology is invalid. To solve this medical issue, NVU was raised. Since Professor Lo, E.H. raised it in 2003, NVU has been focused on neuroscience. It is convinced widely that protecting NVU is the most potential strategy to treat brain stroke $[8,9]$. This new idea stands on the deeper appreciation of the close relationships between structure and function of cerebral cells. NVU is regarded as a functional and structural unite of brain with cerebral function. It consists of microvessels, astrocytes, neurons, extracellular matrix and other types of gliocytes. Complicated interactions among these cells can never be ignored for both physiology and pathology of brain. Therefore, the raising of NVU gives a possibility to study and treat cerebral vascular diseases better.

\section{C-P protected NVU from stroke in vivo and in vitro}

Here, several typical pathologic changes in neurons, astrocytes, and endothelial cells which are regarded as the main components of NVU were observed on I/R rats and OGD/R damaged NVU models. These changes were in accordance with previous reports [25-27]. More importantly, C-P was proved to be able to protect the three main types of cells of NVU by enhancing favorable factors and reducing oxidative stress, inflammation, and BBB injury.

The indexes observed in this research included protective and adverse factors. Typical markers of oxidative stress injury and inflammation such as MDA, LDH, NO, TNF- $\alpha$, IL-1 $\beta$, IL-6 and NF-kB/p65 are used to indicate the extent of brain injury [25-29]. The two pathologies not only severely damage neurons but also break BBB [26, 30,31] which is an important structure of NVU. In this experimental system, C-P was shown to protect NVU from oxidative stress injury and inflammation in vivo and in vitro. Meanwhile, its protection on BBB was supported by the evidences of the decreased permeability of BBB and the increased Claudin-5 in vitro.

Neuroprotective factors that protect the NVU in integrity are required to benefit at least neurons and vessels which are regarded as the core of NVU. Among these protective factors, EPO and VEGF are of the capacities prominently. EPO in brain is mainly secreted by astrocyte [32-35]. It protects cerebral cells from NO, inflammation, DNA degradation, and granulocyte infiltration [36-38] and promotes angiogenesis and neurogenesis in brain [35]. Another notable factor is VEGF which promotes endothelial proliferation, migration, and vascular sprouting. Recent studies suggest that it is of capacities to promote neuron survival $[39,40]$, neurogenesis $[40,41]$, and neural plasticity [42]. Additionally, the most im- portant factor for neuron development and recovery is GAP-43 which is essential for axon growth and neural plasticity [43] and typically increased during axon recovery $[44,45]$. All of the levels of these factors to some extent indicate the capacities of NVU against injuries and to recovery after brain stroke. Notably, C-P protected NVU in vivo and in vitro via promoting these three protective factors. All the performances of C-P suggested that C-P is a candidate medicine to protect NVU via multiple neuroprotection.

\section{That catalpol and puerarin in combination treat stroke is multiple protection}

Combination of Rehmannia glutinosa Libosch and Radix Puerariae was commonly used in Traditional Chinese Medicine to treat brain stroke [46,47]. As reported previously, catalpol (the primary active ingredient of Rehmannia glutinosa Libosch) and puerarin (the primary active ingredient of Radix Puerariae) inhibited inflammation via decreasing TNF- $\alpha$ and NF-KB [48, 49]. In term of anti-oxidative stress, they performed excellently by decreasing NO [50, 51]. Besides, enhancing EPO also was proved to be very involved in their protection on brain $[52,53]$. Although catalpol and puerarin are of promoting angiogenesis and neural plasticity after brain stroke, the mechanisms are different. Bodies of reports confirmed that catalpol-induced this neural generation is relative to VEGF [52] and GAP-43 [54] which haven't been proved to be involved in puerarin-induced angiogenesis; while in aspect of anti-inflammation, more articles are focused on puerarin which inhibits inflammation through lowering IL-6 and IL-1 $\beta$ [55]. Hence, it seems that there is synergistic effect between catalpol and puerarin in neuroprotection.

\section{Cellular interactions of NVU in physiology, pathology, and responses to drugs are worth studying in future}

Cellular interactions are of great importance in physiological and pathological NVUs. Cells and tissues of NVU are close in structure, and even touch with each other. These lead the direct interactions between the cells $[6,23]$. However, the interactions can be harmful for spreading harmful factors or be protective for favorable factors. These interactions occur in NVU when brain stroke happens [7, 24]. Based on this, every member in NVU has its specific and essential role in physiology, pathology, and even the responses to drugs. Bodies of researches have confirmed the pivotal effects of endothelial cells and astrocytes on physiological and pathological neurons [56-58]. This confirms the pivotal roles of affiliated cells in NVU. However, dose the absence of a specific type of cells, astrocytes or endothelial cells for in- 
stance, affect the responses of NVU to drugs? This is a worth research gap to be filled.

\section{Conclusions}

C-P protected the three main types of cells of NVU in vivo and in vitro depending on anti-oxidative stress injury, anti-inflammation, protecting BBB, and up-regulating protective factors. These data demonstrate that C-P is a candidate medicine to treat brain stroke.

\section{Acknowledgements}

This work was supported by the Natural Science Foundation of China (No. 81473549, No.81402441), the National Key New Drug Development Project of China (2014ZX09304-306-04), the Fundamental Research Funds for the Central Universities (XDJK2014D023 and XDJK2015D016) and the China Postdoctoral Science Foundation (No. 2014M562272).

\section{Competing Interests}

The authors have declared that no competing interest exists.

\section{References}

1. Kleindorfer D, Lindsell CJ, Brass L, Koroshetz W, Broderick JP. National US estimates of recombinant tissue plasminogen activator use ICD-9 codes substantially underestimate. Stroke. 2008; 39:924-8. doi: 10.1161/STROKEAHA.107.490375.

2. Party ISW. National Sentinel Stroke Audit 2010 Round 7. London, UK: Royal College of Physicians of London. 2011.

3. Hacke, W., Kaste M, Bluhmki E, Brozman M, Dávalos A, Guidetti D, et al. Thrombolysis with alteplase 3 to 4.5 hours after acute ischemic stroke. N Engl J Med. 2008; 359: 1317-29 doi: 10.1056/NEJMoa0804656.

4. Lees, K.R., Bluhmki E, von Kummer R, Brott TG, Toni D, Grotta JC, et al. Time to treatment with intravenous alteplase and outcome in stroke: an updated pooled analysis of ECASS, ATLANTIS, NINDS, and EPITHET trials. Lancet. 2010; 375: 1695-703. doi: 10.1016/S0140-6736(10)60491-6.

5. Jauch EC, Saver JL, Adams HP Jr, Bruno A, Connors JJ, Demaerschalk BM, et al. Guidelines for the Early Management of Patients with Acute Ischemic Stroke: A Guideline for Healthcare Professionals from the American Heart Association/American Stroke Association. Stroke. 2013; 44:870-947. doi: 10.1161/STR.0b013e318284056a.

6. Muoio, V., P. Persson, and M. Sendeski. The neurovascular unit-concept review. Acta Physiol (Oxf). 2014; 210: 790-8. doi: 10.1111/apha.12250.

7. Del Zoppo GJ. The neurovascular unit in the setting of stroke. J Intern Med. 2010; 267: 156-71. doi: 10.1111/j.1365-2796.2009.02199.x.

8. Lo, E.H., T. Dalkara, and M.A. Moskowitz. Mechanisms, challenges and opportunities in stroke. Nat Rev Neurosci. 2003; 4: 399-415.

9. Moskowitz, M.A., E.H. Lo, and C. The science of stroke: mechanisms in search of treatments. Neuron. 2010; 67: 181-98. doi: 10.1016/j.neuron.2010.07.002.

10. Xue, Q., Liu Y, Qi H, Ma Q, Xu L, Chen W, et al. A novel brain neurovascular unit model with neurons, astrocytes and microvascular endothelial cells of rat. Int J Biol Sci. 2013; 9: 174-89. doi: 10.7150/ijbs.5115.

11. Oin W, Mao X, Chen W, et al. HPLC-APCI-MS/MS method for the determination of catalpol in rat plasma and cerebrospinal fluid: application to an in vivo pharmacokinetic study. J Pharm Biomed Anal. 2012; 70:337-43. doi: 10.1016/j.jpba.2012.05.016

12. Yuan H, ZHANG J-f, Wang Q, DENG L, XU X. Focal irritant, allergia, haemolyticus and acute toxicity of Catalpol and Puerarin for injection. Chinese Pharmacological Bulletin. 2013; 29:880-1.

13. Liu Y, Xue Q, Li X, Zhang J, Fu Z, Feng B, et al. Amelioration of Stroke-Induced Neurological Deficiency by Lyophilized Powder of Catalpol and Puerarin. Int J Biol Sci. 2014; 10: 448-56. doi: 10.7150/ijbs.8571.

14. Zhang C, Ma Q, Xue Q, Chen G, Xu X. [Protective effect of Zige lyophilized powder on hypoxia/reoxygenation injury of human umbilical vein endothelial cells]. Zhongguo Zhong yao za $\mathrm{zhi}=$ Zhongguo zhongyao zazhi $=$ China journal of Chinese materia medica, 2012; 37:997-1001.

15. Yuan H, Zhang JF, Wang Q, XU X. Determination of Catalpol and Puerarin Contents and Their Related Substances in Zige Freeze-Dried Powder for Inection by RP-HPLC. Chinese Pharmaceutical Journal. 2011; 46:1276-9.
16. E.Z Longa, P.R. Weinstein, S. Carlson, R. Cummins. Reversible middle cerebral artery occlusion without craniectomy in rats. Stroke.1989; 20: 84-91.

17. J. Chen, Y. Li, L .Wang, Z. Zhang, D. Lu, M. Lu, et al. Therapeutic benefit of intravenous administration of bone marrow stromal cells after cerebral ischemia in rats. Stroke. 2001; 32: 1005-11.

18. Liu $Y$, Xue Q, Tang Q, Hou M, Qi H, Chen G, et al. A simple method for isolating and culturing the rat brain microvascular endothelial cells. Microvasc Res. 2013; 90:199-205. doi: 10.1016/j.mvr.2013.08.004.

19. Ciccarelli R, D'Alimonte I, Santavenere C, D'Auro M, Ballerini P, Nargi E, et al. Cysteinyl-leukotrienes are released from astrocytes and increase astrocyte proliferation and glial fibrillary acidic protein via cys-LT1 receptors and mitogen-activated protein kinase pathway. Eur J Neurosci. 2004; 20:1514-24.

20. Suvarna NU, O'Donnell JM. Hydrolysis of N-methyl-D-aspartate receptor-stimulated cAMP and CGMP by PDE4 and PDE2 phosphodiesterases in primary neuronal cultures of rat cerebral cortex and hippocampus. J Pharmacol Exp Ther. 2002; 302:249-56.

21. Zhu H, Wang Z, Xing Y, Gao Y, Ma T, Lou L, et al. Baicalin reduces the permeability of the blood-brain barrier during hypoxia $<\mathrm{i}>$ in vitro $</ \mathrm{i}>$ by increasing the expression of tight junction proteins in brain microvascular endothelial cells. J Ethnopharmacol. 2012; 141:714-20. doi: 10.1016/j.jep.2011.08.063

22. Veszelka S, Pásztói M, Farkas AE, Krizbai I, Ngo TK, Niwa M, et al. Pentosan polysulfate protects brain endothelial cells against bacterial lipopolysaccharide-induced damages. Neurochem Int. 2007; 50:219-28.

23. Abbott NJ, Rönnbäck L, Hansson E. Astrocyte-endothelial interactions at the blood-brain barrier. Nat Rev Neurosci. 2006; 7:41-53.

24. Hawkins BT, Davis TP. The blood-brain barrier/neurovascular unit in health and disease. Pharmacol Rev. 2005; 57:173-85.

25. Chen H Yoshioka H, Kim GS, Jung JE, Okami N, Sakata H, et al. Oxidative stress in ischemic brain damage: mechanisms of cell death and potential molecular targets for neuroprotection. Antioxid Redox Signal. 2011; 14:1505-17. doi: 10.1089 /ars. 2010.3576

26. Sandoval K E, Witt K A. Blood-brain barrier tight junction permeability and ischemic stroke. Neurobiol Dis. 2008; 32:200-19. doi: 10.1016/j.nbd.2008.08.005

27. Huang J, Upadhyay $\mathrm{UM}, \mathrm{Rj} \mathrm{T}$. Inflammation in stroke and focal cerebral ischemia. Surg Neurol. 2006; 66:232-45.

28. Harari OA, Liao JK. NF-kB and innate immunity in ischemic stroke. Ann N Y Acad Sci. 2010; 1207:32-40. doi: 10.1111/j.1749-6632.2010.05735.x

29. Lakhan SE, Kirchgessner A, Hofer M. Inflammatory Mechanisms In Ischemic Stroke: Therapeutic Approaches. J Transl Med. 2009; 7:97. doi: 10.1186/1479-5876-7-97.

30. Ronaldson, P. T. and T. P. Davis. Targeting transporters: Promoting blood-brain barrier repair in response to oxidative stress injury. Brain Res. 2015; 1623: 39-52. doi: 10.1016/j.brainres.2015.03.018

31. Rochfort K D, Collins L E, Murphy R P, et al. Downregulation of Blood-Brain Barrier Phenotype by Proinflammatory Cytokines Involves NADPH Oxidase-Dependent ROS Generation: Consequences for Interendothelial Adherens and Tight Junctions. PLoS One. 2014; 9:e101815. doi: 10.1371/journal.pone.0101815.

32. Bond W S, Rex T S. Evidence That Erythropoietin Modulates Neuroinflammation through Differential Action on Neurons, Astrocytes, and Microglia. Front Immunol. 2014; 5:523. doi: 10.3389/fimmu.2014.00523.

33. Genc S, Koroglu TF, Genc K. Erythropoietin and the nervous system. Brain Res. 2004; 1000:19-31.

34. Li Y, Lu ZY, Ogle M, Wei L. Erythropoietin Prevents Blood Brain Barrier Damage Induced by Focal Cerebral Ischemia in Mice. Neurochem Res. 2007; 32:2132-41.

35. Wang L, Zhang Z, Wang Y, Zhang R, Chopp M. Treatment of stroke with erythropoietin enhances neurogenesis and angiogenesis and improves neurological function in rats. Stroke. 2004; 35:1732-7.

36. Nguyen AQ, Cherry BH, Scott GF, Ryou MG, Mallet RT. Erythropoietin: Powerful protection of ischemic and post-ischemic brain. Exp Biol Med (Maywood). 2014; 239:1461-75. doi: 10.1177/1535370214523703.

37. Spandou E, Soubasi V, Papoutsopoulou S, Karkavelas G, Simeonidou C Kaiki-Astara A. Erythropoietin prevents hypoxia/ischemia-induced DNA fragmentation in an experimental model of perinatal asphyxia. Neuroscience Letters. 2004; 366:24-8.

38. Sun Y, Zhou C, Polk P, Nanda A, Zhang JH. Mechanisms Of Erythropoietin-Induced Brain Protection In Neonatal Hypoxia-Ischemia Rat Model. J Cereb Blood Flow Metab. 2004; 24:259-70.

39. Birte, Svensson, Marion, Peters, Hans-Georg, K?nig, et al. Vascular Endothelial Growth Factor Protects Cultured Rat Hippocampal Neurons Against Hypoxic Injury via an Antiexcitotoxic, Caspase-Independent Mechanism. J Cereb Blood Flow Metab. 2002; 22:1170-5.

40. Greenberg D A, Jin K. Vascular Endothelial Growth Factors (VEGFs) and Stroke. Cell Mol Life Sci. 2013; 70:1753-61. doi: 10.1007/s00018-013-1282-8.

41. Jin K, Zhu Y, Sun Y, Mao XO, Xie L, Greenberg DA. Vascular endothelial growth factor (VEGF) stimulates neurogenesis in vitro and in vivo. Proc Natl Acad Sci USA. 2002; 99:11946-50.

42. Song S, Park J T, Na J Y, et al. Early expressions of hypoxia-inducible factor lalpha and vascular endothelial growth factor increase the neuronal plasticity of activated endogenous neural stem cells after focal cerebral ischemia. Neural Regen Res. 2014; 9:912-8. doi: 10.4103/1673-5374.133136. 
43. Shen Y, Mani S, Donovan SL, Schwob JE, Meiri KF. Growth-associated protein- 43 is required for commissural axon guidance in the developing vertebrate nervous system. J Neurosci. 2002; 22:239-47.

44. Carmichael ST, Archibeque I, Luke L, Nolan T, Momiy J, Li S. Growth-associated gene expression after stroke: evidence for a growth-promoting region in peri-infarct cortex. Exp Neurol. 2005; 193:291-311.

45. Murphy TH, Corbett D. Plasticity during stroke recovery: from synapse to behaviour. Nat Rev Neurosci. 2009; 10:861-72. doi: 10.1038/nrn2735.

46. Gong X, Sucher N J. Stroke therapy in traditional Chinese medicine (TCM): prospects for drug discovery and development. Phytomedicine. 2002; 9:478-84.

47. Sun K, Fan J, Han J. Ameliorating effects of traditional Chinese medicine preparation, Chinese materia medica and active compounds on ischemia/reperfusion-induced cerebral microcirculatory disturbances and neuron damage. Acta Pharm Sin B. 2015; 5:8-24.

48. Mahdy H M, Mohamed M R, Emam M A, et al. The anti-apoptotic and anti-inflammatory properties of puerarin attenuate 3-nitropropionic-acid induced neurotoxicity in rats. Can J Physiol Pharmacol. 2014; 92:252-258. doi: 10.1139/cjpp-2013-0398.

49. Bi J, Jiang B, Zorn A, et al. Catalpol inhibits LPS plus IFN- $\gamma$-induced inflammatory response in astrocytes primary cultures. Toxicol In Vitro. 2012;27:543-550. doi: 10.1016/j.tiv.2012.09.023.

50. $\mathrm{Li} \mathrm{Y}, \mathrm{Bao} \mathrm{Y}, \mathrm{Bo}$, et al. Catalpol protects primary cultured astrocytes from in vitro ischemia-induced damage. Int J Dev Neurosci. 2008; 26:309-317. doi: 10.1016/j.ijdevneu.2008.01.006.

51. Xiaohong $X$, Xiaoxiang $Z$. Potential involvement of calcium and nitric oxide in protective effects of puerarin on oxygen-glucose deprivation in cultured hippocampal neurons. J Ethnopharmacol. 2007; 113:421-6.

52. Hui-Feng Z, Dong W, Yong L, et al. Catalpol increases brain angiogenesis and up-regulates VEGF and EPO in the rat after permanent middle cerebral artery occlusion. Int J Biol Sci. 2010; 6:443-53.

53. Li G, Xunming J, Juexian S, et al. Puerarin protects against ischemic brain injury in a rat model of transient focal ischemia. Neurol Res. 2009; 31:402-406(5). doi: 10.1179/174313209X444017.

54. Liu J, Liu Y, Zou W, et al. Catalpol Upregulates Hippocampal GAP-43 Level of Aged Rats with Enhanced Spatial Memory and Behavior Response. J Behav Brain Sci. 2012; 02:495-504

55. Yao X J, Yin J A, Xia Y F, et al. Puerarin exerts antipyretic effect on lipopolysaccharide-induced fever in rats involving inhibition of pyrogen production from macrophages. J Ethnopharmacol. 2012;141:322-330. doi: 10.1016/j.jep.2012.02.038

56. Shuzhen G, Woo Jean K, Josephine L, et al. Neuroprotection via matrix-trophic coupling between cerebral endothelial cells and neurons. Proc Natl Acad Sci USA. 2008; 105:7582-7. doi: 10.1073/pnas.0801105105.

57. Ouyang Y B, Xu L, Liu S, et al. Role of Astrocytes in Delayed Neuronal Death: GLT-1 and its Novel Regulation by MicroRNAs. Adv Neurobiol. 2014; 11: 171-88. doi: 10.1007/978-3-319-08894-5 9.

58. Takano T, Oberheim N, Cotrina M L, et al. Astrocytes and ischemic injury. Stroke. 2009; 40(Suppl):S8-12. doi: 10.1161/STROKEAHA.108.533166. 